(C) Dereito Vol.28, n02:43-60 (Xullo-Decembro, 2019) • ISSN 1132-9947

\title{
TELEOLOGÍA DEL DERECHO PENAL DE MENORES
}

Teleology of the criminal law of minors

DOI: http://dx.doi.org/10.15304/dereito.28.2.5641

\section{Alejandra Marlene Gómez Barrera}

Doctora en gestión y resolución de conflictos

Universidade de Vigo

antigona1387@gmail.com

\section{Resumen}

Tomando en consideración las diferencias cualitativas entre adultos y los menores de edad se ha erigido un Derecho Penal especializado y modalizado, para encargarse de las conductas delictivas cometidas por personas menores de edad, ello para brindar una respuesta encaminada a la reinserción social y familiar del adolescente. Si bien es cierto este Derecho utiliza las hipótesis penales planteadas en el Derecho Penal de adultos, cuenta con principios e instituciones especializadas. Los estados firmantes de la Convención sobre los Derechos del Niño se han comprometido a establecer una edad por debajo de la cual no se pueda sujetar a un menor de edad al sistema penal. Conocer las características de los menores de edad es fundamental para entender el porqué de un derecho especial, pero sobre todo para desarrollar un sistema que responsa a la finalidad de reinserción social y familiar del adolescente.

Palabras clave: Delincuencia juvenil; Derecho Penal; sanción penal.

\section{Abstract}

Considering the qualitative differences between adults and minors, a specialized and modalized Criminal Law has been established to deal with criminal behavior committed by minors, in order to provide a response aimed at the social and family reintegration of the adolescent. While it is true that this law uses the criminal hypotheses raised in adult criminal law, it has specialized principles and institutions. The signatory states of the Convention on the Rights of the Child have committed themselves to establish an age below which a minor can not be subject to the penal system. Knowing the characteristics of minors is fundamental to understand why a special right, but above all to develop a system that responds to the purpose of social and family reintegration of the child.

Keywords: Juvenil delinquency; Criminal Law; penal sanctions.

\section{SUMARIO}

1.- INTRODUCCIÓN.; 2.- EDAD MÍNIMA DE RESPONSABILIDAD PENAL PARA MENORES.; 3.- SUJETOS DEL DERECHO PENAL DE MENORES.; 4.CARACTERÍSTICAS DE LA DELINCUENCIA JUVENIL.; 5.- FINALIDAD DEL DERECHO PENAL DE MENORES.; 6.- CONCLUSIÓN.; 7.- BIBLIOGRAFÍA.

Recibido: 13/09/2019. Aceptado: 28/11/2019. 


\section{SUMMARY}

1. INTRODUCTION.; 2.- MINIMUM AGE OF CRIMINAL RESPONSIBILITY FOR MINORS ; 3.- SUBJECTS OF THE CRIMINAL LAW OF MINORS .; 4.CHARACTERISTICS OF THE YOUTH CRIME; 5.- PURPOSE OF THE CRIMINAL LAW OF MINORS .; 6.- CONCLUSION .; 7.- BIBLIOGRAPHY.

\section{INTRODUCCIÓN}

La minoría de edad es la base para implementar una respuesta diferenciada por parte del Estado ${ }^{1}$, cuando un menor de edad comete un delito, se debe tener en consideración lo señalado por RODRÍGUEZ MANZANERA, respecto de que la imputabilidad se adquiere con el desarrollo de los aspectos afectivo, volitivo e intelectivo ${ }^{2}$, lo anterior sumado al hecho de que:

«...los modernos avances de la Biología, la Psicología y los estudios criminológicos sobre el incremento de la delincuencia juvenil, acogidos por Cuello Calón, Quintano Ripollés, Luzón Domingo, Palacio y Sánchez-Izquierdo y Serrano Gómez, venían evidenciado la diferencia cualitativa existente entre el menor y el adulto ${ }^{3}$.»

En este sentido la existencia de un sistema diferenciado ${ }^{4}$ de justicia deberá responder a las siguientes preguntas: ¿A quiénes se va a aplicar? y ¿Cuál es su finalidad? Respecto del primer cuestionamiento, se debe determinar, a partir de la cual se exigirá la responsabilidad de un menor ante la comisión de delitos, valorándose los efectos que pueden tener, tanto de eficacia a través de la experiencia de legalidad como de estigmatización, además de plantear cuál será la respuesta o el proceder con los menores que cometan delitos y se encuentren por debajo de ese límite inferior señalado 5 .

Asimismo, determinar sí se persigue un fin preventivo o bien uno represivo, y si es el caso del primero, aclarar si se trata de prevención especial o bien general, pues de ello dependerán en gran medida las sanciones a aplicar y la forma en que se ejecuten.

Las características de este Derecho Penal de Menores son ${ }^{6}$ :

1. Únicamente se aplica a los menores que cometen conductas delictivas, dejando de lado a los menores en situaciones irregulares o de desamparo.

\footnotetext{
1 J. D., HIDALGO MURILLO, Hacia una teoría procesal en justicia para adolescentes, Flores Editor, México, 2016, p. 18.

2 D., LARA EGURROLA/M., FRÍAS ARMENTA, "Imputabilidad penal: el caso de los menores", en VV. AA. (M. Frías Armenta, coord.) Niñez, adolescencia y problemas sociales, Plaza y Valdés, México, 2009, pp. 248-249.

${ }^{3}$ A., MARTÍN CRUZ, op. cit., p. 118.

${ }^{4}$ R., VILLANUEVA CASTILLEJA, "Consideraciones técnicas especializadas", en VV.AA. (R., Villanueva Castilleja, coord.), La contemporaneidad del pensamiento de Aureliano Hernández Palacios en el ámbito de los menores de edad que han infraccionado la ley penal, Academia Mexicana de Ciencias Penales, México, 2008, p. 11.

${ }^{5}$ Pronunciamiento de la Comisión Nacional de Derechos Humanos, Racionalización de la Pena de Prisión, México 2016, p. 54.

${ }^{6}$ Ibídem, p. 50.
} 
2. Se trata de un sistema legal, ya que únicamente las actuaciones de las autoridades deben respetar las garantías procesales y los Derechos Humanos

3. La medida únicamente se impondrá después de haberse acreditado la responsabilidad del menor en los hechos que se le imputan.

4. Es un derecho autónomo, en cuanto a sus instituciones y la aplicación de consecuencias jurídicas, aunque comparte los presupuestos de la ley penal.

5. Su aplicación va encaminada a fines de previsión especial reeducación y reinserción del menor.

\section{EDAD MÍNIMA DE RESPONSABILIDAD PENAL PARA MENORES}

De acuerdo con el art. 1 de la Convención sobre los Derechos del Niño (CND) "...se entiende por niño todo ser humano menor de dieciocho años de edad, salvo que, en virtud de la ley que sea aplicable, haya alcanzado antes la mayoría de edad."

Los menores de edad son personas que se encuentran en desarrollo, entendiendo éste como el proceso mediante el cual el ser humano adquiere habilidades y herramientas, físicas, psicológicas, cognoscitivas y sociales, para ajustar su comportamiento a los parámetros socialmente establecidos $^{7}$, situación que resulta determinante al establecer la forma en que el Estado va a intervenir tratándose de un menor infractor.

Tomando en consideración lo anterior, así como el presupuesto de culpabilidad necesario para exigir responsabilidad penal basado en la capacidad de entender y querer las consecuencias de la conducta delictiva, la Convención sobre los Derechos del Niño (20 de noviembre de 1989) en su artículo 40.3 a) establece como obligación de los Estados edad mínima para exigir responsabilidad penal y asimismo la regla 4 de las Reglas Mínimas de Naciones Unidas para la Administración de Justicia de Menores recomienda que el comienzo de la edad mínima de responsabilidad penal no deba fijarse a una edad muy temprana ello tomando en consideración las circunstancias que acompañan la madurez emocional, mental e intelectual de los niños; por ello el Comité de los Derechos del Niño en su observación general número 10 ha instado a los Estados a establecer en por lo menos 12 años la edad mínima de responsabilidad penal e incluso continuar elevándola ${ }^{8}$, pues exigir responsabilidad penal por debajo de esa edad parece contrario a la mínima intervención y al interés superior del niño ya que los menores que tienen esta edad resultan inimputables, ya que según la psicología evolutiva, éstos carecen de la madurez para entender las consecuencias de sus actos frente al Estado.

\footnotetext{
7 B., CRUZ MÁRQUEZ, "Presupuestos de la Responsabilidad penal del menor: una necesaria revisión desde la perspectiva adolescente", Anuario de la Facultad de Derecho de la Universidad Autónoma de México, núm. 15, 2011, p. 244.

${ }^{8}$ Comité de los Derechos del Niño Observación General No. 10 (2007) p. 11.
} 
Lo anterior no significa que las conductas cometidas por los menores que se encuentran por debajo del límite inferior sean ignoradas, sino que deben aplicarse otras estrategias de índole administrativo para atenderlas siempre salvaguardando el interés superior del menor y sus derechos humanos.

Como ejemplo de lo anterior tenemos que en México el artículo 18 de la Constitución Política de los Estados Unidos Mexicanos establece que el sistema integral de justicia para adolescentes se aplica a las personas mayores de 12 años y menores de 18 años que cometan delitos, por lo que las personas menores de 12 años de edad que cometan delitos sólo podrán ser sujetos de asistencia social, en ese mismo sentido la LO 5/2000, de 12 de enero, Reguladora de la Responsabilidad Penal de Menores (LORPM/España) establece en su artículo 3 que el sistema de responsabilidad penal de menores se aplica a las personas mayores de 14 años y menores de 18 años que cometan un delito, en tanto que a los menores de 14 años de edad que cometan un delito se les aplicaran las medidas de Protección Previstas en el Código Civil y en la LO 1/1996, de 15 de enero, de Protección Jurídica del Menor.

Si bien muchos países han aplicado el criterio del Comité de los Derechos del Niño de 12 o más años (Alemania, Argentina, Canadá, Cuba, Italia y Francia), aún hay Estados que tienen un límite mínimo de responsabilidad establecido a una edad muy temprana (Escocia (8 años) y Estados Unidos de Norteamérica (7 años)).

\section{SUJETOS DEL DERECHO PENAL DE MENORES}

Como se ha señalado son las diferencias cualitativas entre los adolescentes y los adultos ${ }^{9}$ las que han determinado que la dogmática jurídico-penal (a partir de la segunda mitad del siglo XX) considere que los menores de edad que cometen delitos deberían ser sometidos a una jurisdicción diferente, de acuerdo con las gráficas 1 y 2 se advierte que este derecho especial se aplica en la mayoría de los Estados a las personas entre $12 / 14$ años y 18 años $^{10}$, por lo que se les proporcionara un tratamiento de acuerdo con sus características particulares ${ }^{11}$, materializando así la flexibilidad y reconociendo la autonomía progresiva 12, con la finalidad de llegar a la aplicación de la ley más acorde a su desarrollo ${ }^{13}$.

\footnotetext{
${ }^{9}$ M., SARRE, "Ejecución de Sanciones y Medidas Penales privativas de libertad", en VV. AA., Derechos humanos en la Constitución. Comentarios de jurisprudencia constitucional e interamericana, T. II, Instituto de Investigaciones Jurídicas-Universidad Nacional Autónoma de México, México 2015, p. 1838.

${ }^{10}$ Se toma este rango de edades tomando en consideración que la mayoría de los Países tanto americanos como europeos establece una edad mínima de responsabilidad igual o mayor a 12 años.

${ }^{11}$ A., MARTÍN CRUZ, "El menor y el semiadulto ante la moderna psicología evolutiva y ante la LO 8/2006", en VV. AA. (A., Jorge Barreiro/B., Feijo Sánchez, eds.), Nuevo Derecho Penal juvenil: una perspectiva interdisciplinar. ¿Qué hacer con los menores delincuentes?, Atelier, Barcelona, 2008, p. 118.

12 O., GARCÍA PÉREZ, "La reforma de 2006 de la Ley de Responsabilidad Penal de los Menores: la introducción del modelo de seguridad ciudadana", en VV. AA. (A., Jorge
} 
Por lo anterior es necesario señalar que el desarrollo del ser humano (proceso en el que ocurren cambios cualitativos y cuantitativos) se da en por lo menos cuatro ámbitos: físico, cognitivo, emocional y social, los cuales se encuentran fuertemente relacionados, pues las capacidades cognitivas pueden depender de la salud física y emocional, así como de la experiencia o el desarrollo social; en tanto que el desarrollo social, está influido por la maduración biológica, la comprensión cognitiva y las reacciones emocionales ${ }^{14}$.

A pesar de que los psicólogos evolutivos que estudian los procesos del desarrollo humano han concluido que este proceso de desarrollo se produce de forma continua, es posible y necesario para su estudio debido a que presentan características específicas, determinar períodos o etapas de este proceso de desarrollo ${ }^{15}$, de ahí que de acuerdo con RICE ${ }^{16}$ las personas que tienen entre 10 y 19 años se encuentran en la etapa del ciclo vital llamada adolescencia la cual a su vez se divide en dos etapas: la primera adolescencia (entre 10 y 14 años) y la segunda adolescencia (entre15 y 19 años) ${ }^{17}$.

Lo anterior significa que las personas a quienes se aplica el Derecho Penal de Menores se encuentran en la etapa de la adolescencia, la cual según RICE es "una etapa de transición entre la niñez y la vida adulta por la que deben pasar los individuos antes de que puedan tomar lugar como mayores"18. Esta etapa comienza al inicio de la pubertad, período del desarrollo biológico en el que ocurre la maduración sexual del hasta entonces niño y concluye cuando el individuo alcanza su pleno desarrollo físico, cognitivo y social ${ }^{19}$, lo que se exterioriza con la adopción de roles sociales propios de los adultos ${ }^{20}$.

De acuerdo con PIAGET ${ }^{21}$ la adolescencia coincide con la etapa de las operaciones intelectuales abstractas ${ }^{22}$, en la que el sujeto es capaz de

Barreiro/B., Feijo Sánchez, eds.), Nuevo Derecho Penal Juvenil: una perspectiva interdisciplinar ¿Qué hacer con los menores delincuentes?, Atelier, Barcelona, 2008, pp. 42-43. M. J., CRUZ BLANCA, Derecho Penal de menores (Ley Orgánica 5/2000, Reguladora de la responsabilidad Penal de Menores), Edersa, Madrid, 2002, p. 127. M., BERNUZ BENITEZ, "Justicia de menores española y nuevas tendencias penales. La regulación del núcleo duro de la delincuencia juvenil", Revista Electrónica de Ciencia Penal y Criminología, núm. 7, 2005.

${ }^{13}$ M., SHEIN, El Niño precolombino, Villicaña, México, 1986, pp. 15-17.

${ }^{14}$ F. P., RICE, Desarrollo Humano. Estudio del ciclo vital, Traducción de Ma. Elena Ortiz Salinas, Prentice-Hall Hispanoamericana, México, 1997, pp. 9 y 10.

15 J., DELVAL, El desarrollo humano, Siglo Veintiuno de España, 7a edición, Madrid, 2006, p. 130.

${ }^{16}$ F. P., RICE, op. cit. pp. 5-7.

17 Informe especial sobre Derechos Humanos de las y los jóvenes en el Distrito Federal, 2010-2011.

${ }^{18}$ F. P., RICE, op. cit. p. 326.

${ }^{19}$ F. P. RICE, op. cit. p. 327. DELVAL, J., op. cit., p. 544.

${ }^{20}$ A., MARTÍN CRUZ, op. cit. p. 141. A., COLÁS TURÉGANO, Derecho Penal de menores, Tirant lo Blanch, Valencia, 2011, p. 23.

21 J. PIAGET, Seis estudios de psicología, Traducido por Jordi Marfá, Labor S.A., Barcelona, 1991, p. 14. 
construir sistemas y teorías utilizando el pensamiento hipotético-deductivo y llegar a conclusiones sin la necesidad de observación, de ahí que pueda anticiparse a situaciones futuras a través del razonamiento lógico; asimismo comienza a interesarse por cuestiones intelectuales (religión, política, literatura, etcétera) sobre los cuales reflexiona con expectativa de cambio.

El desarrollo de este pensamiento formal conlleva el desarrollo social del adolescente, lo que le permitirá integrarse a la sociedad a través de la elaboración de un proyecto de vida, de la interiorización de normas ${ }^{23}$, valores y roles; ello después de haber conseguido la "conquista de su personalidad"24.

Por su parte el desarrollo social es un proceso lento, que inicia en la familia, y poco a poco se produce mediante la interacción del individuo con la sociedad, a través de los agentes de socialización, la escuela, la iglesia, los grupos deportivos, las instituciones públicas e incluso grupo de pares, con lo que la conducta se adecúa a las perspectivas y expectativas sociales, morales y legales ${ }^{25}$.

Respecto del desarrollo moral-legal KOHLBERG ${ }^{26}$ señala que los adolescentes se encuentran en el nivel convencional en el que el individuo se somete a las reglas, expectativas y convenciones de la sociedad o de la autoridad, y las defiende precisamente porque son reglas, expectativas o convenciones de la sociedad. Aquí se encuentran la mayoría de los adolescentes y adultos de nuestra sociedad y de otras sociedades.

De lo anterior, se concluye que a la par de las etapas del desarrollo de la persona en las que principalmente se toma como referencia el de cambio biológico físicos (aumento de talla, peso, aparición de caracteres sexuales secundarios, etcétera) se pueden identificar otros parámetros para señalar diferentes etapas o niveles relacionados con los procesos cognitivos, morales e incluso legales, considerados para exigir la culpabilidad disminuida - tanto durante el proceso como en la determinación de la sanción y su ejecución ${ }^{27}$.

No debe perderse de vista que la adolescencia es un fenómeno psicosocial presente en las sociedades occidentales desarrolladas, en las que no basta la adultez biológica para adquirir la adultez social (autonomía e independencia de los padres), lo que ha ocasionado que esta etapa de transición se prolongue, lo que ocasiona inseguridad, tensiones y conflictos que se han considerado característicos de esta etapa ${ }^{28}$.

${ }^{22}$ DELVAL señala que el desarrollo de las operaciones formales, se ve relacionado con la complejidad de la sociedad en la que el individuo se desarrolla. J., DELVAL, op. cit., p. 562.

${ }^{23}$ Es en este periodo en el que ocurre la interiorización del sistema legal de la sociedad en la que el sujeto se desenvuelve.

24 J., PIAGET, op. cit., pp. 83-94.

${ }^{25}$ A., MARTÍN CRUZ, op. cit. p. 145.

${ }^{26}$ L., KOHLBERG, Psicología del desarrollo moral, Desclee de Brouwer, Bilbao, 1992, pp. 72-95.

${ }^{27}$ I., SÁNCHEZ GARCÍA DE PAZ, I., "Minoría de edad y derecho penal juvenil, Aspectos político criminales", EGUZKILORE, número 12, San Sebastián, diciembre, 1998, p. 70.

${ }^{28}$ A., MARTÍN CRUZ, op. cit. p.149. 
Las circunstancias específicas del menor representan una responsabilidad sui generis, específica al caso de las personas en desarrollo que cometen delitos, en donde las circunstancias concretas de carácter personal, familiar, social, económica deben ser tomadas en consideración, ${ }^{29}$ en este sentido se pronuncia BELOFF quien define la justicia juvenil como:

«...el conjunto de normas e instituciones creadas para dar respuesta a la situación de una persona menor de dieciocho años de edad imputada o encontrada responsable de haber cometido un delito ${ }^{30}$.»

\section{CARACTERÍSTICAS DE LA DELINCUENCIA JUVENIL}

La mayoría de las personas cometen alguna falta o delito antes de la mayoría de edad ${ }^{31}$, por ejemplo, en España los 13 años sería la edad en que la mayoría de los jóvenes manifiestan haber cometido su primera infracción legal, aumentando la frecuencia infractora con la edad, hasta los 17 años $^{32}$, de ahí que se considere como un fenómeno normal ${ }^{33}$.

El fenómeno de la delincuencia juvenil es además ubicuo, pues no depende directamente de algún factor de tipo económico o de clase social, es decir no hay una causa-efecto directa entre un factor y la comisión de un delito, lo que no descarta el reconocimiento de factores de riesgo ${ }^{34}$, tal como se expone a continuación.

Es un tipo de delincuencia episódica ${ }^{35}$, ya que se trata de una situación específica que no se constituye como un modo de vida (aunque puede ser el inicio de una vida delictiva $)^{36}$ y su comisión no implica que ingresen a los sistemas de justicia estatales ${ }^{37}$; además de que estas conductas

${ }^{29}$ M. J., JiMENEZ DÍAZ, "Edad y menor", en VV. AA. (J. M., Juárez López, coord.), El menor como víctima y victimario de la violencia social (estudio jurídico), DYKINSON, Madrid, 2010, p. 69.

30 M., BELOFF, "Los adolescentes y el sistema penal. Elementos para una discusión necesaria en la Argentina actual", Revista jurídica de la Universidad de Palermo, número 1, 2005, p. 108.

${ }^{31}$ C., VÁZQUEZ GONZÁLEZ, op. cit., p.21.

32 De acuerdo con el Informe sobre Conductas antisociales y delictiva: un $98.8 \%$ de los adolescentes de la muestra refiere haber cometido alguna vez en su vida una conducta ilícita leve, siendo las más comunes: bajar música mediante internet $(66 \%$ de la muestra), consumir bebidas alcohólicas siendo menores de edad (63\%), haberse emborrachado (41\%), consumir cannabis (28\%) y participar en peleas (22\%). S., REDONDO ILLESCAS/A., MARTÍNEZ CATENA/A., ANDRÉS PUEYO, "Factores de éxito asociados a los programas de intervención son menores infractores, departamento de personalidad, evaluación y tratamiento psicológico", Facultad de Psicología, Universidad de Barcelona, 2011, p. 19. M., BERNUZ BENITEZ, op. cit., pp. 23-24.

${ }^{33}$ I., ROBLES SANTOS, "Delincuencia y justicia juvenil en España. Estado actual según las fuentes oficiales", p. 3.

34 A., MARTÍNEZ-CATENA/S., REDONDO ILLESCAS, "Carreras delictivas juveniles y tratamiento", Zierbitzuan 54, Abendua diciembre 2013, p. 172.

${ }^{35}$ C., VÁZQUEZ GONZÁLEZ, "Predicción y prevención de la delincuencia juvenil según las teorías del desarrollo social", Revista de Derechos, vol. XIV, julio 2003, p. 135.

${ }^{36}$ S., REDONDO ILLESCAS/A., MARTÍNEZ CATENA/A., ANDRÉS PUEYO, op. cit., pp. 3940.

37 En España entre el 70 y $80 \%$ de los delincuentes menores de edad sancionados tras cometer su primer delito no reinciden. C., PÉREZ VAQUERO, "La Justicia juvenil en el Derecho Europeo", Derecho y Cambio Social, 2014, p. 23. 
temerarias en la mayoría de los casos dejan de ocurrir en la edad adulta ${ }^{38}$, al respecto VÁZQUEZ GONZÁLEZ señala que:

«La investigación ha asociado una serie de patrones de conducta antisocial al proceso evolutivo de la edad (RUTTER Y GILLER, 1988). Entre 1 y 5 años aparecen en los niños las primeras conductas socialmente desaprobadas, que tienen que ver con incidentes en casa, rabietas, agresiones a los hermanos o algún pequeño robo en el hogar. A partir del inicio de la escolarización y hasta los 12 años disminuyen las conductas desaprobadas por los adultos. Los niños van adquiriendo patrones de conducta social y aprenden a obedecer las instrucciones de los adultos. De los 13 a los 18 años se opera, en general, un aumento de la cantidad y variedad de conductas antisociales (delincuente por crisis de adolescencia) aparecen fenómenos como la rebeldía (...). No aumenta en esta edad el número de individuos que participan en actividades delictivas juveniles, que en realidad va siendo paulatinamente menor. Pero aquellos que las llevan a cabo aumentan progresivamente su gravedad, a la vez que aumenta el número de detenciones, debido a que los jóvenes han llegado ya a la edad penal. Aumenta, por tanto, la probabilidad de ser detenidos y castigados por el sistema de justicia y se inician las llamadas carreras delictivas. De los 20 a los 30 se produce un cese de las actividades delictivas de muchos jóvenes ${ }^{39}$.»

La delincuencia juvenil es también accidental en tanto que generalmente su comisión depende mucho de la oportunidad, pues mayormente se cometen sin planificarse y aprovechándose de la situación -oportunidad40.

Además, es de carácter simbólico, pues, en la mayoría de las veces, el adolescente se ve impulsado por la búsqueda de reconocimiento por parte de su grupo de pares, de ahí que se cometa en grupo ${ }^{41}$, pues en buena medida los adolescentes actúan de forma grupal (esta característica deriva de la importancia que en esta etapa del desarrollo humano toma el grupo de pares) ${ }^{42}$. Respecto de la comisión en grupo, se debe tener en cuenta que "En la pandilla encuentran sentido de pertenencia a un grupo con el que se sienten identificados y en el que encuentran su identidad" ${ }^{\prime 3}$.

38 En este tenor las Directrices de las Naciones Unidas para la prevención de la delincuencia juvenil (Directrices de Riad) en su apartado 1.5.e cuando proclaman «el reconocimiento del hecho de que el comportamiento o conducta de los jóvenes que no se ajusta a los valores y normas generales de la sociedad son con frecuencia parte del proceso de maduración y crecimiento y tienden a desaparecer espontáneamente en la mayoría de las personas cuando llega a la edad adulta».

39 C., VÁZQUEZ GONZÁLEZ, Delincuencia juvenil. Consideraciones penales y criminológicas, COLEX, Madrid, 2003, p. 36.

${ }^{40}$ Ibídem, p. 41.

${ }^{41}$ C., VÁZQUEZ GONZÁLEZ, "Predicción y prevención de la delincuencia juvenil según las teorías del desarrollo social" ..., op. cit., p. 136.

42 C., VÁZQUEZ GONZÁLEZ, C., Delincuencia juvenil. Consideraciones penales y criminológicas..., op. cit. p. 38.

${ }^{43}$ J. C., RAMÍREZ SALAZAR, Introducción a la justicia penal para adolescentes, Flores, México, 2016, p. 223. C., NIETO MORALES, "Menores, jóvenes, educación, drogas y 
Lo anterior se ve influido por el hecho de que en las sociedades modernas se ha venido prolongando la adolescencia/juventud, lo que ha producido que, si bien legal y biológicamente se ha alcanzado la madurez, la mayoría de edad, las personas aún no desempeñan roles de adultos, por lo que su desarrollo social se ve retrasado ${ }^{44}$.

Es importante resaltar que, aunque no existe uno o varios factores que provoquen la delincuencia de menores, si es posible identificar factores de riesgo ${ }^{45}$, tales como los hogares disfuncionales, la violencia en el hogar, el alcoholismo, la drogadicción de los padres, el absentismo y fracaso escolar y la marginación social ${ }^{46}$.

Así pues, de acuerdo con FELDMAN la clase baja tiene más probabilidad de ser investigada por sospechosa, de permanecer en prisión, ser llevada a juicio, ser hallada culpable y recibir un castigo severo, que cualquiera de las otras clases sociales. Lo anterior se atribuye en parte al estereotipo de que la delincuencia es cosa de pobres ${ }^{47}$. Según RAMÍREZ SALAZAR:

«La relación entre delito y clase baja, se puede explicar atendiendo a la escasez de posibilidades, como desempleo, subempleo, marginación y hacinamiento en grandes ciudades, la opción de tráfico de drogas, la integración a las filas de la delincuencia organizada como alternativa de la pobreza o como alternativa aleatoria en el financiamiento de una vida delictiva ${ }^{48} . \gg$

Si bien no existe una causa-consecuencia inamovible entre estos y la delincuencia, sí hay incidencia de uno o más de estos factores en la vida de los menores que se encuentran vinculados a la comisión de un delito ${ }^{49}$, es de señalarse también que la intensidad de esta influencia, varía según el menor ${ }^{50}$.

justicia", Revista Castellano-Manchega de Ciencias Sociales, número 14, 2012, pp. 1819. Este punto debe tenerse presente en el momento de revisar las hipótesis para la imposición de la medida de internamiento, ya que la comisión en pandilla resulta una agravante del delito.

${ }^{44}$ En este tenor GARCÍA PÉREZ considera que dadas las características de los menores en la adolescencia y toda vez que los cambios sociales han prolongado esta etapa de la vida, el límite inferior para la intervención penal debería elevarse a dieciséis años, siendo que los menores de esta edad reciban una respuesta de tipo civil o administrativo. Cfr. A., COLÁS TURÉGANO, Derecho Penal de menores, Tirant lo Blanch, Valencia, 2011, p. 125. De ahí que en algunos países se establezca un sistema entre el Derecho Penal de Menores y Derecho Penal de Adultos que se ocupe de las conductas delictivas realizadas por personas entre 18 y 21 años de edad con la finalidad de aplicar una sanción atenuada, como es el caso de Portugal y en su momento también de España sin que en este último se haya podido materializar

45 W. A., HEIN, "Factores de riesgo y delincuencia juvenil, revisión de la literatura nacional e internacional", Fundación Paz Ciudadana, Chile, 2004, pp.1-21.

46 J., MORANT VIDAL, "La delincuencia juvenil", Acaip, Valencia, 2003, pp. 4-5.

47 F., FELDMAN, Comportamiento criminal: un análisis psicológico, FCE, México, 1989, p. 114.

48 J. C., RAMÍREZ SALAZAR, op. cit., p. 222.

${ }^{49}$ M., DÍAZ MARTÍNEZ/J. M., LACRUZ LÓPEZ/A. I., LUACÉS GUTIÉRREZ/M. D., SERRANO TÁRRAGA/C., VÁZQUEZ GONZÁLEZ, Derecho Penal juvenil, DYINSON, 2a edición, Madrid, 2007, p. 102.

${ }^{50}$ A., MARTÍNEZ-CATENA/S., REDONDO ILLESCAS, op. cit., p. 175. 
BARRAZA PÉREZ ${ }^{51}$ esquematiza los siguientes factores generadores de delincuencia juvenil:

- $\quad$ Centros de rehabilitación deficientes

- Hacinamiento poblacional

- Índices altos de drogadicción

- $\quad$ Falta de impulso al deporte

- Índices de escolaridad deficientes

- $\quad$ Alto índice de desempleo

- Graves niveles de desintegración familiar

En ese mismo sentido se pronuncia NIETO MORALES quién después de un estudio en Sevilla logra identificar factores de riesgo recurrentes en los casos de delincuencia juvenil que incluso le permiten esbozar un perfil del menor infractor en Sevilla, tomando en consideración la edad, el delito, la familia, el grupo de pares y el consumo de estupefacientes ${ }^{52}$.

Los adolescentes delincuentes, como los niños y niñas, pueden ser afectados por las consecuencias sociológicas y morales de la discriminación; DE LA TORRE MARTÍNEZ señala como principales consecuencias la estigmatización, la exclusión, la marginalización y el olvido ${ }^{53}$. A efecto de eludir la estigmatización, se evitan los registros de antecedentes delictivos de los adolescentes, ya que no pueden considerarse como los adultos ${ }^{54}$.

\section{FINALIDAD DEL DERECHO PENAL DE MENORES}

La finalidad del Derecho Penal de Menores es establecer un sistema penal diferenciado tanto en lo procesal como en la ejecución de las medidas, pero ¿para qué se necesita un sistema diferenciado? Se ha dicho que la adolescencia es una etapa de transición de la infancia a la vida adulta, lo que significa que las personas adolescentes que cometen un delito se incorporaran en el futuro a la vida en sociedad, es por ello que la finalidad este Derecho especial es la integración de la persona adolescente a su familia y comunidad.

Así lo establece el art. 40.1 CDN, los sistemas penales minoriles deben «...promover la reintegración social del niño y de que este asuma una

\footnotetext{
${ }^{51}$ R., BARRAZA PÉREZ, Delincuencia juvenil y pandillerismo, Porrúa, México, 2016, p. 54.

52 C., NIETO MORALES, "Perfil de los menores en conflicto con la ley", Trabajo Social y Servicios Sociales, número 6, Semestre 2, 2012, pp. 50- 56. En México, el tema de los adolescentes delincuentes, se relaciona con el tema de las niñas, niños y adolescentes en situación de calle ( $y$ otras situaciones de vulnerabilidad), aumentando los factores de riesgo como son las adicciones y la violencia. M. D., VALENZUELA REYES, Derechos Humanos de Niñas, Niños y Adolescentes ¿Utopía o realidad?, Porrúa, México, 2016, pp. 221-228.

53 C., DE LA TORRE MARTÍNEZ, El derecho a la no discriminación en México, Porrúa, Comisión nacional de Derechos Humanos, México, 2006, pp. 8, 23, 24 y 52.

54 Sistema Integral de Justicia para Adolescentes. Es contrario a la Ley suprema considerar como antecedente penal de una persona, en un proceso penal federal para adultos, una conducta antisocial que cometió cuando contaba con dieciséis a las y estaba en vigor el texto del art. 18 de la Constitución Política de los Estados Unidos Mexicanos, reformado y adicionado mediante decreto publicado en el Diario Oficial de la Federación el 12 de diciembre de 2005. Décima Época, Primera Sala registro: 160265.
} 
función constructiva en la sociedad." provocando un rompimiento con su pasado esta es el "desarrollo de una estructura de personalidad que contrasta profundamente con la personalidad anterior ${ }^{55}$.»

Esta finalidad se consigue a través de la consecuencia jurídica que recae a la comisión del delito ${ }^{56}$, así resulta necesario precisar que como señala GARCÍA RIVAS $^{57}$, la sanción es un medio flexible de resocialización del adolescente, pero no sólo eso, sino que la intervención -penal en este caso- se encamina a evitar que ese adolescente en particular cometa nuevos delitos, sea mientras aun es menor de edad o siendo ya mayor prevención especial; por lo que la respuesta sancionadora a los delitos debe regirse tanto por el principio de proporcionalidad como por las características propias del menor, pues de este modo se responde a las necesidades específicas del menor.

Las medidas que se imponen a los menores que cometen hechos delictivos, no dejan de ser consecuencias jurídicas derivadas del ius puniendi del Estado, sin embargo, las medidas sancionadoras son consecuencias especiales, con características y finalidad específicas. La principal diferencia entre la pena y la medida sancionadora radica en que ésta implica un castigo/retribución, en tanto que la medida busca la modificación de una situación, en materia de menores.

Las sanciones que derivan de este proceso penal minoril han sido llamadas genéricamente como medidas y constituyen la respuesta individualizada que el Estado aplica en específico a la persona menor de edad que ha sido encontrada responsable de la comisión de un delito, y tienen como finalidad la reinserción social y familiar del menor, a través del cumplimiento de actividades en libertad o bien en internamiento.

Por lo que, esta regulación de las medidas impuestas a los adolescentes debe conjugar el objetivo educativo del Derecho Penal de adolescentes, con la aun prevaleciente retribución que caracteriza al Derecho Penal de adultos ${ }^{58}$, por lo que el objeto principal de un sistema especializado penal para adolescentes, es la reinserción o reintegración e incluso readaptación del sujeto menor de edad, ello a través de la intervención educativa en la

\footnotetext{
${ }^{5}$ B., PHILIPS, Sociología, del concepto a la práctica, Mc Graw Gill, México, 1988, p. 69. J., DONDÉ MATUTE, Principio de legalidad penal perspectivas del Derecho Penal e internacional, Porrúa, México, 2010, p. 137-138. Convención sobre los Derechos del Niño art. 40.1 Los Estados Parte reconocen el derecho de todo niño de quien se alegue que ha infringido las leyes penales o a quien se acuse o declare culpable de haber infringido esas leyes a ser tratado de manera acorde con el fomento de su sentido de la dignidad y el valora, que fortalezca el respeto del niño por los derechos humanos y las libertades fundamentales de terceros y en la que se tengan en cuenta la edad del niño y la importancia de promover la reintegración del niño y de que éste asuma una función constructiva en la sociedad.

${ }^{56}$ S., GARCÍA RAMÍREZ, Justicia Penal, Porrúa, México 1998, p. 25.

57 N., GARCÍA RIVAS, El poder punitivo en el Estado Democrático, Ediciones de la Universidad de Castilla-La Mancha Cuenca, España, 1996, p. 37.

58 Situación que también corre en las medidas cautelares, tal es el caso de la medida de alejamiento de la víctima, la deja de lado el interés superior del menor y lo subsume a los intereses de terceros, en este caso de la víctima.
} 
ejecución de las mismas ${ }^{59}$. Lo anterior obliga la colaboración de técnicos especializados en el trato de menores de edad en situaciones de vulnerabilidad y conflicto con la ley, pues es a través de actividades terapéuticas, educativas, culturales, deportivas y comunitarias que el menor podrá desarrollar las cualidades que le permitan interactuar en la sociedad de forma armónica y positiva ${ }^{60}$.

Como ejemplo tenemos el artículo 2.1 de la Lei 166/99 establece que las medidas aplicadas a los menores que han cometido un delito se basan en la educación con la finalidad de que el menor se integre a la comunidad de forma digna y responsable. Las medidas, en ese mismo tenor la Ley Nacional del Sistema Integral de Justicia Penal en México (LNSIJP) establece en su artículo 28 que la uno de los objetivos de la aplicación de medidas es la reintegración social y familiar del adolescente. Por su parte la LORPM resalta la resocialización al establecer en su artículo 55 que las actividades realizadas durante el internamiento deben promover la vida del adolescente como parte de la sociedad, esto teniendo en cuenta que se trata de un sistema sancionador educativo tal y como se establece en el punto 11 de la Exposición de Motivos de la misma ley. En tanto que el Código de la Infancia y Adolescencia colombiano establece que las medidas impuestas a los adolescentes que cometen delitos tienen una finalidad protectora, educativa y restaurativa (art. 178).

Debe quedar claro que la "educación" a la que se refiere el Derecho Penal de Menores, no es la educación de las instituciones académicas, sino la EDUCACIÓN que implica obtener las herramientas necesarias para la socialización, de tal forma que el adolescente que haya cumplido una sanción como resultado de la comisión de un delito se incorpore a su familia, comunidad y sociedad de una forma positiva tanto para él como para las personas que lo rodean. Desde esta perspectiva, las medidas no constituyen una retribución, sino una herramienta para orientar positivamente el proceso de socialización del menor infractor, procurando su desarrollo psicológico y personal de maduración, y con ello su adecuada integración social ${ }^{61}$; ello por ser necesario dadas las posibles carencias que hubo en el proceso de socialización previo.

59 Apartado 7 EM. M-J, DOLZ LAGO, "La nueva responsabilidad penal del menor", (Comentarios a la Ley Orgánica 5/2000, de 12 de enero), Ediciones Revista General de Derecho, Valencia, 2000, p. 36-37. M. C., ALASTUEY DOBÓN, "El Derecho Penal de menores: evolución y rasgos esenciales de la Ley Orgánica 5/2000", VV. AA. (J. L., Diez Ripolles/C. M., Romero Casabona/L., Gracia Martín/J. F., Higuera Guimerá, edits.), La ciencia del Derecho Penal, ante el nuevo siglo. Libro homenaje al Profesor Doctor D. José Cerezo Mir, Tecnos, Madrid, 2002, p. 1547.

60 La participación de las redes de apoyo y la comunidad en el proceso de ejecución de las medidas, resulta fundamental sin embargo ahondar más en el tema sobrepasa los límites del presente trabajo para mayor información véase M. J., FUNES TIVAS, "Procesos de socialización y participación comunitaria: estudio de un caso". B., PEÑA ACUÑA, "La socialización a través de las redes", REDMARKA, 2011. M. D., FERNÁNDEZ FUSTES, "La mediación penal con menores infractores en Inglaterra y Gales", en VV. AA. (E., González Pillado, coord.), Mediación con menores infractores en España y los países de su entorno, Tirant lo Blanch, Valencia, 2012, pp. 359-362.

${ }^{61}$ M. J., CRUZ BLANCA, op. cit., p. 103. 
Así pues, las sanciones a aplicar, se relacionan directamente con el fin del sistema, es decir, si estamos frente a un sistema represivo, las medidas se encaminan a castigar al menor, privándolo simple y llanamente de derechos y/o libertades a fin de causar menoscabo en su esfera jurídica, proporcional al que él ha causado; por otro lado, si lo que se pretende es la prevención, la aplicación de medidas sancionadoras-educativas constituyen la mejor respuesta, ya que por un lado el menor verá que su conducta tiene consecuencias jurídico-penales ${ }^{62}$.

En ese sentido, sí se dice que el Derecho Penal de Menores persigue la prevención general los demás menores percibirán que aun siendo menores pueden ser responsables penalmente de sus conductas; pero el menor infractor también recibirá la atención que precisa para su óptima integración a la sociedad y su pleno, óptimo e integral desarrollo (prevención especial) ${ }^{63}$.

En consecuencia, retomando las palabras de GARCÍA RAMÍREZ, cuando se habla de Derecho de menores se hace en el marco de una sociedad juvenil, sin referirse a un Derecho menor, sino a un marco jurídico que reconoce las características de los sujetos menores y busca garantizar su interés superior ${ }^{64}$; en consecuencia, ubica el Derecho Penal de Menores, dentro del derecho social como el más previsor ${ }^{65}$.

Los tratamientos para menores delincuentes se dirigen a dotar a los sujetos de nuevas habilidades y competencias de comunicación e interacción humanas; implican esencialmente la modificación de los factores de riesgo, de ahí la importancia de identificarlos ${ }^{66}$.

Como ejemplo tenemos que, en el sistema mexicano, la finalidad establecida tanto en la Constitución como en la Ley especializada es la reinserción social y reintegración del menor a su familia, siempre que ello no resulte contrario a su interés superior y pleno desarrollo de su persona y sus capacidades. De acuerdo con esta regulación, los medios para conseguir estos fines son (arts.18 Constitucional, 154 y 153 LNSIJPA):

- Garantizar el cumplimiento de sus derechos, a efecto de brindarle la experiencia de legalidad que le sirva para modificar la forma en que se relaciona con su entorno de forma armoniosa.

- Posibilitar su desarrollo personal, a través de la educación (académica y de algún oficio), del arte, el deporte y la salud, además del fomento de los vínculos con el exterior y redes de apoyo.

\footnotetext{
${ }^{62}$ Es decir, si el fin de la aplicación de la pena es la intimidación general, para inhibir los impulsos delictivos de autores potenciales indeterminados, estamos frente a una teoría preventivo-general de la pena y será preventivo-especial si busca que el autor del delito no reitere su conducta. D. E., FERNÀNDEZ MUÑOZ, La pena de prisión, propuesta para sustituirla o abolirla, Instituto de Investigaciones Jurídicas - Universidad Nacional Autónoma de México, Ciudad de México, 1993, p. 48.

${ }^{63}$ M.T., MARTÍN LÓPEZ, Justicia con menores infractores y menores víctimas, Ediciones de la Universidad de Castilla-La Mancha, Cuenca, 2000, pp. 17-23.

${ }^{64}$ S., GARCÍA RAMÍREZ, cit. op., pp. 206-207.

${ }^{65}$ Ibidem, pp. 208 y 212.

${ }^{66}$ A., MARTÍNEZ-CATENA/S., REDONDO ILLESCAS, op. cit., p. 177.
} 
- Escuchar, tomar en cuenta su opinión y fomentar su participación activa en la elaboración y ejecución de su Plan Individualizado de Actividades.

- Minimizar los efectos negativos que la medida de sanción pudiera tener en su vida futura.

La Suprema Corte de Justicia en México ha establecido que para conseguir la reinserción social de una persona es necesario tener en consideración «...sus carencias, ayudarla a que las reconozca y pueda superarlas a través, entre otros, del deporte, el trabajo, y la capacitación para el mismo, para lo cual debe gozar de buena salud; sin olvidar el conocimiento que debe tener de los problemas que existen en el lugar donde tiene su casa y vive con su familia. Lo anterior para que al regresar a la sociedad no vuelva a cometer más delitos ${ }^{67}$.»

Por su parte el Derecho Penal de Menores en España, establece igualmente que su naturaleza es sancionadora educativa, cuyo fin es la resocialización tal y como lo establecen las Sentencias del Supremo Tribunal Constitucional 36/1991, de 14 de febrero (fundamentos jurídicos 6 y 7) y 60/1995, de 17 de marzo (fundamentos jurídicos 5 y 6)-, mismas que señalan que tomando como punto de partida que el fin del proceso penal de menores es la resocialización, se debe realizar una intervención educativa. En este sentido la LORPM señala que este sistema busca favorecer los vínculos sociales del menor con su familia (55.1 LORPM), a través de la colaboración de entidades públicas y privadas en este proceso.

Tomando en consideración lo anterior tanto España como México prevén la aplicación de medidas sancionadoras de contenido educativo tales como: la amonestación, el apercibimiento, la prestación de servicios a la comunidad, la asistencia a sesiones de asesoramiento o actividades análogas, integración a programas especializados en teoría género e incluso ambos sistemas establecen que el internamiento en régimen cerrado debe tener un contenido educativo con la finalidad de que el menor se integre a su familia y comunidad.

Sin embargo, cabe señalar que, en el caso de España CRUZ MÁRQUEZ señala que la verdadera finalidad de la medida de internamiento en régimen cerrado contemplada en la LORPM sino la exclusión social de los menores, pues el internamiento obstaculiza la educación ya que viven en un medio artificial lo que dificulta du integración a la vida en libertad ${ }^{68}$.

\section{CONCLUSIÓN}

El reconocimiento y consideración de las diferencias que existen entre los adultos y las personas que aún no lo son, es la base de un Derecho que busca responder de manera diferenciada a las conductas delictivas

\footnotetext{
${ }^{67}$ Suprema Corte de Justicia de la Nación, Análisis sobre la nomenclatura empleada en el Nuevo Sistema de Justicia Penal, Previsto en la Constitución Política de los Estados Unidos Mexicanos, Suprema Corte de Justicia de la Nación, 2012, p. 138.

68 B., CRUZ MÁRQUEZ, La medida de internamiento y sus alternativas en el Derecho Penal Juvenil, DYKINSON, Madrid, 2007, pp. 30-46.
} 
cometidas por menores de edad; en esta respuesta son consideradas las etapas de desarrollo humano.

Así, una de las principales características del Derecho Penal de Menores es que, aunque comparte el mismo presupuesto que el Derecho Penal ordinario -la comisión de un delito- difiere considerablemente en la consecuencia jurídica además de las peculiaridades que deben ser consideradas en el proceso; la identificación y reconocimiento de sus características, es la base para la formación de un trato diferenciado entre el tratamiento de adultos y menores de edad que cometen delitos.

La diferenciación entre las personas adultas y las personas adolescentes es la base para la exigencia de culpabilidad atenuada, cuya regulación se encuentra en legislaciones especiales como es el caso de la Lei 166/99, de 14 de septiembre, Tutelar Educativa (Portugal); la LO 5/2000, de 12 de enero, Reguladora de la Responsabilidad Penal de los Menores (España); la Ley 1098 de 2006, Código de la infancia y la adolescencia (Colombia) y la Ley Nacional del Sistema Integral de Justicia Penal para Adolescentes (México), esto solo por mencionar algunos ejemplos.

Siendo que de acuerdo con la Convención Sobre los Derechos del Niño la teleología de este Derecho Penal de Menores es la reinserción o reintegración e incluso readaptación del sujeto menor de edad, a su familia, comunidad y sociedad, ello a través de una medida sancionadora basada en la educación. De este modo, el tema medular de la finalidad de las medidas no es el contenido de las leyes y ordenamientos que las regulan, sino la intervención educativa en la ejecución de las mismas, la cual recae en manos de los pedagogos, psicólogos, trabajadores sociales y cualquier otro profesionista que resulte necesario.

\section{BIBLIOGRAFÍA}

A., COLÁS TURÉGANO, Derecho Penal de menores, Tirant lo Blanch, Valencia, 2011.

A., MARTÍNEZ-CATENA/S., REDONDO ILLESCAS, "Carreras delictivas juveniles y tratamiento", Zierbitzuan 54, Abendua diciembre, 171185 2013. <https://doi.org/10.5569/1134-7147.54.12>

A., MARTÍN CRUZ, "El menor y el semiadulto ante la moderna psicología evolutiva y ante la LO 8/2006", en VV. AA. (A., Jorge Barreiro/B., Feijo Sánchez, eds.), Nuevo Derecho Penal juvenil: una perspectiva interdisciplinar. ¿Qué hacer con los menores delincuentes?, Atelier, Barcelona, 2008.

B., CRUZ MÁRQUEZ, La medida de internamiento y sus alternativas en el Derecho Penal Juvenil, DYKINSON, Madrid, 2007.

B., PEÑA ACUÑA, "La socialización a través de las redes", REDMARKA, 124, 2011. <https://doi.org/10.17979/redma.2011.02.07.4732>

B., PHILIPS, Sociología, del concepto a la práctica, Mc Graw Gill, México, 1988.

D., LARA EGURROLA/M., FRÍAS ARMENTA, "Imputabilidad penal: el caso de los menores", en VV. AA. (M. Frías Armenta, coord.) Niñez, adolescencia y problemas sociales, Plaza y Valdés, México, 2009. 
B., CRUZ MÁRQUEZ, "Presupuestos de la Responsabilidad penal del menor: una necesaria revisión desde la perspectiva adolescente", Anuario de la Facultad de Derecho de la Universidad Autónoma de México, núm. 15, 2011.

C., DE LA TORRE MARTÍNEZ, El derecho a la no discriminación en México, Porrúa, Comisión nacional de Derechos Humanos, México, 2006.

C., PÉREZ VAQUERO, "La Justicia juvenil en el Derecho Europeo", Derecho y Cambio Social, 2014.

C., NIETO MORALES, "Perfil de los menores en conflicto con la ley", Trabajo Social y Servicios Sociales, número 6, Semestre 2, 2012, disponible en línea en http://roderic.uv.es/bitstream/handle/10550/33473/47.pdf?sequenc $\mathrm{e}=1$ (consultado el 21 de noviembre de 2018)

C., NIETO MORALES, "Menores, jóvenes, educación, drogas y justicia", Revista Castellano-Manchega de Ciencias Sociales, número 14, 2012.

C., VÁZQUEZ GONZÁLEZ, Derecho penal juvenil europeo, DYKINSON, Madrid, 2005.

C., VÁZQUEZ GONZÁLEZ, Delincuencia juvenil. Consideraciones penales y criminológicas, COLEX, Madrid, 2003.

C., VÁZQUEZ GONZÁLEZ, "Predicción y prevención de la delincuencia juvenil según las teorías del desarrollo social", Revista de Derechos, vol. XIV, julio 2003, disponible en línea http://mingaonline.uach.cl/pdf/revider/v14/Art08.pdf

Comité de los Derechos del Niño Observación General No. 10 (2007)

D. E., FERNÀNDEZ MUÑOZ, La pena de prisión, propuesta para sustituirla o abolirla, IIJ-UNAM, Ciudad de México, 1993.

F., FELDMAN, Comportamiento criminal: un análisis psicológico, FCE, México, 1989.

F. P., RICE, Desarrollo Humano. Estudio del ciclo vital, Traducción de Ma. Elena Ortiz Salinas, Prentice-Hall Hispanoamericana, México, 1997.

I., ROBLES SANTOS, "Delincuencia y justicia juvenil en España. Estado actual según las fuentes oficiales", disponible en línea en http://www.pensamientopenal.com.ar/system/files/2015/11/doctrin a42427.pdf (consultado el 21 de noviembre de 2018)

I., SÁNCHEZ GARCÍA DE PAZ, I., "Minoría de edad y derecho penal juvenil, Aspectos político criminales", EGUZKILORE, número 12, San Sebastián, diciembre, 1998.

J. C., RAMÍREZ SALAZAR, Introducción a la justicia penal para adolescentes, Flores, México, 2016.

J. D., HIDALGO MURILLO, Hacia una teoría procesal en justicia para adolescentes, Flores Editor, México, 2016.

J., DELVAL, El desarrollo humano, Siglo Veintiuno de España, 7a edición, Madrid, 2006.

J., MORANT VIDAL, "La delincuencia juvenil", Acaip, Valencia, 2003, disponible en línea

en http://www.acaip.info/docu/menores/delincuencia_juvenil.pdf (consultado el 21 de noviembre de 2018) 
J., PIAGET, Seis estudios de psicología, Traducido por Jordi Marfá, Labor S.A., Barcelona, 1991.

L., KOHLBERG, Psicología del desarrollo moral, Desclee de Brouwer, Bilbao, 1992.

M., BELOFF, "Los adolescentes y el sistema penal. Elementos para una discusión necesaria en la Argentina actual", Revista jurídica de la Universidad de Palermo, número 1, 97-122, 2005. < https://doi.org/10.5354/0718-0527.2006.14185>

M., BERNUZ BENITEZ, "Justicia de menores española y nuevas tendencias penales. La regulación del núcleo duro de la delincuencia juvenil", Revista Electrónica de Ciencia Penal y Criminología, núm. 7, 138139, 2005. <https://doi.org/10.7238/idp.v0i22.3000>

M. C., ALASTUEY DOBÓN, "El Derecho Penal de menores: evolución y rasgos esenciales de la Ley Orgánica 5/2000", VV. AA. (J. L., Diez Ripolles/C. M., Romero Casabona/L., Gracia Martín/J. F., Higuera Guimerá, edits.), La ciencia del Derecho Penal, ante el nuevo siglo. Libro homenaje al Profesor Doctor D. José Cerezo Mir, Tecnos, Madrid, 2002.

M. D., FERNÁNDEZ FUSTES, "La mediación penal con menores infractores en Inglaterra y Gales", en VV. AA. (E., González Pillado, coord.), Mediación con menores infractores en España y los países de su entorno, Tirant lo Blanch, Valencia, 2012.

M. D., VALENZUELA REYES, Derechos Humanos de Niñas, Niños y Adolescentes ¿Utopía o realidad?, Porrúa, México, 2016.

M., DÍAZ MARTÍNEZ/J. M., LACRUZ LÓPEZ/A. I., LUACÉS GUTIÉRREZ/M. D., SERRANO TÁRRAGA/C., VÁZQUEZ GONZÁLEZ, Derecho Penal juvenil, DYINSON, 2a edición, Madrid, 2007.

M. J., CRUZ BLANCA, Derecho Penal de menores (Ley Orgánica 5/2000, Reguladora de la responsabilidad Penal de Menores), Edersa, Madrid, 2002.

M-J, DOLZ LAGO, "La nueva responsabilidad penal del menor", (Comentarios a la Ley Orgánica 5/2000, de 12 de enero), Ediciones Revista General de Derecho, Valencia, 2000.

M. J., FUNES TIVAS, "Procesos de socialización y participación comunitaria: estudio de un caso", Revista Española de Investigaciones Sociológicas, No. 67, 187-205, 1994. <https://doi.org/10.2307/40183740>

M. J., JIMENEZ DÍAZ, "Edad y menor", en VV. AA. (J. M., Juárez López, coord.), El menor como víctima y victimario de la violencia social (estudio jurídico), DYKINSON, Madrid, 2010.

M., SARRE, "Ejecución de Sanciones y Medidas Penales privativas de libertad", en VV. AA., Derechos humanos en la Constitución. Comentarios de jurisprudencia constitucional e interamericana, T. II, IIJ-UNAM, México 2015. <https://doi.org/10.17103/reei.32.11>

M., SHEIN, El Niño precolombino, Villicaña, México, 1986.

M.T., MARTÍN LÓPEZ, Justicia con menores infractores y menores víctimas, Ediciones de la Universidad de Castilla-La Mancha, Cuenca, 2000. 
N., GARCÍA RIVAS, El poder punitivo en el Estado Democrático, Ediciones de la Universidad de Castilla-La Mancha Cuenca, España, 1996.

O., GARCÍA PÉREZ, "La reforma de 2006 de la Ley de Responsabilidad Penal de los Menores: la introducción del modelo de seguridad ciudadana", en VV. AA. (A., Jorge Barreiro/B., Feijo Sánchez, eds.), Nuevo Derecho Penal Juvenil: una perspectiva interdisciplinar ¿Qué hacer con los menores delincuentes?, Atelier, Barcelona, 2008.

Pronunciamiento de la Comisión Nacional de Derechos Humanos, Racionalización de la Pena de Prisión, México 2016. <https://doi.org/10.2307/j.ctv1xxvwr.71>

R., BARRAZA PÉREZ, Delincuencia juvenil y pandillerismo, Porrúa, México, 2016.

R., VILLANUEVA CASTILLEJA, "Consideraciones técnicas especializadas", en VV.AA. (R., Villanueva Castilleja, coord.), La contemporaneidad del pensamiento de Aureliano Hernández Palacios en el ámbito de los menores de edad que han infraccionado la ley penal, Academia Mexicana de Ciencias Penales, México, 2008.

S., GARCÍA RAMÍREZ, Justicia Penal, Porrúa, México 1998.

S., REDONDO ILLESCAS/A., MARTÍNEZ CATENA/A., ANDRÉS PUEYO, "Factores de éxito asociados a los programas de intervención son menores infractores, departamento de personalidad, evaluación y tratamiento psicológico", Facultad de Psicología, Universidad de Barcelona, 2011.

W. A., HEIN, "Factores de riesgo y delincuencia juvenil, revisión de la literatura nacional e internacional", Fundación Paz Ciudadana, Chile, 1-21, 2004, disponible en línea http://www.copihueb.com/pazciudadana/publicacion/factores-de-riesgo-y-delincuencia-juvenilrevision-de-la-literatura-nacional-e-internacional/ (consultado el 21 de noviembre de 2018)

\section{Legisgrafía}

Convención sobre los Derechos del Niño (20 de noviembre de 1989)

Lei 166/99, de 14 de septiembre, Tutelar Educativa

LO 5/2000, de 12 de enero, Reguladora de la Responsabilidad Penal de los Menores

LO 1/1996, de 15 de enero, de Protección Jurídica del Menor

Ley 1098 de 2006, Código de la infancia y la adolescencia

Ley Nacional del Sistema Integral de Justicia Penal para Adolescentes

Reglas mínimas de Naciones Unidas para la Administración de justicia de menores 